\title{
The Difference Between the Lifeworld of Children and the World of Physics: A Basic Problem for Teaching and Learning Mechanics ${ }^{1}$
}

\author{
Bruno Redeker
}

Universität Paderborn

The thematization of the difference between the lifeworld and the standpoint of physics should bring into view a difficulty which lies in the learning of physics itself rather than in external conditions. As the most basic problem in the learning and teaching of physics, this difficulty does not simply concern mechanics. But, in this article, mechanics is taken to be exemplary for this basic issue, and in a way which is structurally the same in the thinking of both adults and children.

First, I will thematize the difference between the lifeworld and the world of physics as seen from the perspective of physics. Next, the particular difficulty for the teaching and learning of physics can then be pointed out from the perspective of the lifeworld. Finally, I will note several brief but fundamental considerations in the psychology of learning.

\section{On the Difference Between the Lifeworld and the Standpoint of Physics}

The principal difference between the lifeworld and the standpoint of physics serves as the central thesis for this article. In opposition to this thesis stands the conviction that the difference between the world of daily life, or rather the everyday world, and physics is merely a gradual one. This seems to be the prevalent conviction within the teaching of physics, not so much with respect to modern physics, but rather more with regard to classical physics and in particular to mechanics. In what follows I will use the word "physics" in the sense of classical physics, and in so doing I exclude the physics of relativity, etc.

The conviction that the difference between the everyday world and that of physics is simply a gradual one implies that physics is essentially a method for knowing nature. This is the inductive method, in accordance with which physics gains its knowledge by continuously making daily experience more precise. For example, Newton warns that inductively-gained knowledge should only be allowed to correct by means of more exact and more complete observation, but not by criticizing hypotheses. ${ }^{2}$ This conviction of a merely gradual difference is again to be found in theoretical discussions of a scientific na- 
ture to the effect that "with Physics the foundation of the structures already in the pre-scientific thinking of daily experience [became] established" through the qualitative comparison of "perceivable things and events ... the beginning was made in the construction of a complete ordering of perceivable events," and that the "task of physics [exists] ... in nothing other than the pursuit of this activity in a most ordered way"-with only special "real" and "conceptual tools." "This conviction might also be seen in the writings of modern physicists such as von Weizsäcker who states that "Galileo paved the way for science by describing the world as we actually experience it."

And yet, the inferred properties of free fall for example, contradict everything which daily experience teaches. Experience teaches that falling depends very much on the form, the material, and the weight of the body. A feather, a sheet of paper, or other such things will fall more slowly than a stone, and particularly lightweight objects, particles of smoke for example, can even rise. Furthermore, how fast a sheet of paper falls depends very much on whether it falls face-first, edge-first, or whether it falls as a crumpled-up ball.

No process of making the experienced movement of a train, a ship, a car, a package, or whatever else, more precise can resolve the contradiction of the relevant presupposition at work here: namely that falling motions should be grasped as constantly accelerating motions, that they should be thought of as force-free movements, as movements which always take place without any first cause or any end.

The physicist and philosopher von Weizsäcker, then, also sees the "true achievement" of Galileo's "great step" to lie in the fact that he "ventured to describe the world in a way that we do not experience it." Galileo would certainly not have contradicted such a statement. With respect to both the Copernican doctrine and the Pythagoreans, he was so thoroughly explicit in his admiration of the "spiritual height of those" who, through "the aliveness of their spirits, did violence to their own senses to such an extent that they were able to put whatever was required by reason, above even the most openly contradictory sense impressions." But if sensuous reality was not apprehended in the concepts of physics, what then is conceptualized therein?

The geometry of motion, or more precisely the Euclidean geometry of motion, is what is conceptualized in the concepts of physics. From the standpoint of physics one would speak of a moved mass-point, but in no way could one speak of a well-formed stone as a very beautiful illustration of something, or of an iridescent raindrop in magnificent colors, which through the heat and toil of the day cools the broken lips. Furthermore, such a mass-point moves uniformly. It 
moves horizontally and straight ahead in absolute identity, and not a little more today and a little less tomorrow. Moreover, the straight line is understood as a special instance of the curve in which the mass-point occupies a series of discontinuous positions, one after another.

The exactness of physics is determined by the ideal-exact form of the objects of its knowledge and not through the application of formal, mathematical means of description and representation. These Limesgestalten, as Husserl called them, are not, however, confined to motion. Physics also speaks of those things that we ordinarily experience as color, cold, warmth, light, or electrical current in the sense of ideal-exact forms in accordance with the standard of Euclidean geometry: which is to say as moved elementary-or pointcharges, as a bundle made up of beams with no diameter or electromagnetic waves, as the vibration of molecular and atomic bonds. Physics is not concerned with the lived quality of a shade of color such as red, but rather has to do with the ascertaining of wavelengths. The Limesgestalten of physics are ultimately without any material substance. No one can actually see the wavelengths or wave envelopes of light, nor can anyone touch that point in which the mass of a body was thought to be concentrated. Similarly, no one can actually feel or notice the force which, when seen from the perspective of physics, permanently affects every briefcase that threatens to slip from one's hand. We immediately notice only that the briefcase is heavy, that it has weight. The coherence of the Limesgestalten, thought of as causally lawful, is a coherence of the most remarkable sort when seen from the perspective of daily experience: every force of acceleration is of necessity directed against a force of inertia. On the other hand, a uniform velocity requires the absence of any effect of force so that every alteration in that velocity must be considered conclusively as the consequence of an externally-acting force. When a body is in a plane motion, no force of acceleration acts on it at the instant it has reached its greatest velocity - this force in fact has a value of zero. By comparison, experience teaches us that a great expending of force is needed to maintain a great velocity, whether we consider running, riding a bicycle, or driving a car.

Physics, then, does not find the object of its knowledge in a natural manner, but rather must first bring them forth itself in a mathematical projection. "Projection" in this context means that nature given in sensuous perception is interpreted as a coherence of ideal-exact forms thought of as causally lawful. It means an unmistakable, definite view of the world which has been equally-well characterized by means of an open horizon of its referential totality.

What was traditionally presupposed to be a known reality "existing in absolute objectivity," and which physics increasingly 
approximates by means of its grasp of knowledge in formal, mathematical descriptions, models, theories, etc., we can grasp as the true achievement of Galileo in contrast to the historical Mythos of the natural sciences. This achievement consisted of risking a geometrization of the world which is universal and which stands in a continuity that is thought of as causally lawful. It is mathematical projection of nature that serves as the foundation for modern natural science, and which itself develops from and guides the research activity of that science.

A "mathematization of nature," which would give nature in a "formal coat" by permitting all possible consequences to be developed and worked through, can succeed because the objects of knowledge for physics and its "formal stenography" are both mathematical in kind. This does not mean, however, and should not mean, that physics can no longer be seen as an empirical science. Rather, it can be an empirical science in the genuine sense of that term precisely because it is mathematical. Along with the knowledge about the continuity of the production of the objects of its knowledge, then, mathematical knowledge also includes a knowledge of the bringing-forth of material representations from its object. Correspondingly, the mathematical projection includes a priori the knowledge of the bringing-forth of facts and figures for the conclusive calculation of its Limesgestalten, or rather the knowledge of the bringing-forth of a more or less extended coherence of parts, and all of this leads to the justification of hypotheses regarding this coherence of parts. Such a bringing-forth is the essential trait or tendency of the technical.

Because it is a mathematical science, physics is at the same time essentially a technical science, or a science that demands technology and which, for its part, brings technology forth anew. Already with Galileo, this fundamental technical tendency was exhibited in the performing of experiments. For example, he built a water clock with which to determine the intervals of time in which bodies fall. A wooden plank "12 ells" ( 6.7 meters) in length, "by one-half ell in width and three inches thick" served him as an inclined plane for the purpose of prolonging the interval of time in which a body will fall. He then dug a "very straight" channel in this plank and lined it with "very smooth and clean parchment." In this way Galileo was able to reduce the interference of friction on a rolling body, something which he further reduced by preparing a "very hard, perfectly round and smoothly-polished" brass ball. He then attempted to gloss over the influences of air, lift, and friction by using a ball of the appropriate weight. ${ }^{8}$

In this way Galileo endeavored to produce those facts and figures which his assertions concerning the Limesgestalt warranted: "with over one hundred repetitions we constantly found that the length of 
the course acted as the square of the time, and this proved to be true for every slope of the plane, which is to say for every slope of the channel in which the ball ran."

A science is not an exact science in the modern sense because it collects an abundance of data and then, afterwards, employs formal-mathematical procedures on these data. Neither can it happen that all the facts which are necessary for a conclusive calculation be produced, nor can predictions by means of extrapolation secure the terms under which these predictions would also come true. Extrapolations do not even allow these conditions to be known free of doubt. Correct prognoses, however, which is to say predictions which then also come true, have been a constitutive characteristic of the modern natural sciences from the time of their inception. Thus Galileo risks the prediction that "all bodies would fall at exactly the same speed, if one completely eliminated the resistance of the air,"10 and he offers this prediction without someone first having seen, for example, a stone and a feather falling with the same approximate speed. Furthermore, Galileo held to this prediction even though concrete falling motions contradicted it. He could not have produced a vacuum, but besides that he could never have learned from it how to demonstrate once and for all that his assertion holds true for all bodies. No observation caused him to retract his assertions regarding free fall, including observations from his own experiments. Finally, his measurements could only succeed for him as a very rough approximation. A rolling ball in motion down an inclined plane is very obviously not the same sort of thing as an unrestricted fall.

Numerical difficulties are the rule in physics, and these numerical difficulties are conditioned by the specific limits of the prevailing technical proficiency or skill at measuring. Even more essential, however, is the fact that the ideal-exact object of physics necessarily remains unattainable for every instrumental grasping. As a result, disturbances that are particular to each experiment and the disturbing side effects that are particular to each instrument must to some extent come to be "idealized out." If this were to happen, then the theorem concerning the conservation of energy, for example, would have been retained even though it is also contrary to every measured experience.

Every formation of a hypothesis, a concept, or a law, as well as its verification or rejection, presupposes the mathematical projection. The experiment in physics differs from every other experience in this fundamental sense: in such an experiment new appearances, as well as confirming measurements and observations, would first have been intentionally brought forth in view of the mathematical projection and then, as required, they would be interpreted. The experiment is neither a "question asked of nature," as one can often 
read, nor is it "nature's answer" as given in the results of experimental trials. Rather, the physicist asks and the physicist answers.

If it is the case that physics, as a mathematical science, is an experimental and also inherently a technical science, and if it is also the case that geometric structures are the substratum of physics, then to what extent can physics still be called a science of nature? This can happen only insofar as neither the perceived world nor the perception of it has been derived from the pure substrate of physics or from the continuity of ideal-exact forms thought of as causally lawful. The mere thought of the discontinuous positions of a mass point leads to neither the flight of a swallow, nor to the movement of the moon, nor to a stone with very beautiful colorings and markings-regardless of whether it causes itself to fall or whether it will be thrown-nor does it lead to the motion of things in our environment relative to one another which occur as we move ourselves.

In order to justify hypotheses about a Limesgestalt, physics must nevertheless find something that it can modify as it becomes necessary. If by chance we are lacking the visual perception of the colors in the diversity of their qualities, how should a wave with a length of 510 nanometers come to be represented as a standard for the shade of color "green?" Without the daily experience of motion, the occupying of discontinuous positions by a mass point was never its movement proper, and "the act of transition itself was never imaginable, [a transition] which is always between two instants and two positions so close to one another that one is able to choose between them." In this way, daily experience proves that the nature that was given in sensuous perception is necessarily presupposed by physics, and in this sense physics proves to be a natural science.

The world of sense perception is not, however, a presupposition of physics in the sense of a mere first step, a first step that remained stuck, so to speak, on the way to exactness. Rather, it is the case that physics is neither able to establish itself from itself in such away that from this the continuity of its knowledge can act, nor is it able to guarantee the continuity of every perception without which the everyday experience of its "objects really would have been exceeded," and these "have been seen [among its] steps or activities constantly diversify themselves without ever being able to grasp their outward relations or to penetrate into their truth." ${ }^{12}$ In this way we find ourselves expelled from a dimension of human being-toward-the-world, which Husserl called the "lifeworld" and which Merleau-Ponty characterized as the "world which is always already found prior to all knowledge, and from which all knowledge speaks... and in which we first learned what things such as a forest, a meadow, and a river are."13

If we want to know what the extent of the difference is between the lifeworld and the standpoint of physics with respect to the learning 
of physics, then we must take up and maintain the meaning of the lifeworld as found in the glance: the lifeworld as an unthematically-guiding, pre-reflective dimension of human knowledge not only to accompany our being-toward-the-world but rather to direct it. This can be seen in terms of what and how we await or expect something and how to use it. Because from within the horizons of the experience and understanding of that dimension of human knowledge which is grounded in the lifeworld, we have always already understood "as what" and "for what" something is which comes to our knowledge-for example, whether we recognize something as threatening, pleasing, reliable, etc.-prior to our encounter with any particular individual.

If we want to know the extent of the difference between the lifeworld and the standpoint of physics with respect to the learning of physics, then we must rigorously think that the pre-understanding of the lifeworld is first of all not known from those idealizations, or rather Limesgestalten, which come from the exact sciences of which they are at the same time the substratum. More clearly than is the case with adults, the pre-understanding of the lifeworld comes to expression for children as our viewpoint-toward-the-world, and furthermore it becomes more clear that this pre-understanding of the lifeworld knows nothing naturally of the ideal-exact substratum of physics.

In order to see this, it is appropriate to make unthematically guiding horizons of experience and understanding in the pre-understanding of the lifeworld, as unthematically functioning, into a theme. Beginning with such a thematization, there was an investigation with schoolchildren between the ages of 12 and 16 which presented them with a large pendulum that was simply a 50 kilo lump of rock fastened to the ceiling by a five-meter-long rope. Students from the Hauptschule, the Realschule, and the Gymnasium all took part in this investigation. A report by Martin Wagenschein, a classic in the field of the teaching of physics in Germany, served as the model for the pendulum experiment. Furthermore, contrary to the analysis I have given here, Wagenschein's report concerning his teaching experiences with the large pendulum appears to suggest that Limesgestalten pertaining to physics were seen in the lifeworld with relatively few problems. Wagenschein reports that just the "mere viewing" of the gentle swings of the rock could lead to an understanding of speed as a series of moments, so that the teacher had to say nothing, or hardly anything. Thus, at the end it was only necessary to summarize by saying, "By the term 'instant of time' a physicist means a stopping or standing-still without duration. It is shorter than every instant, smaller than every moment, underlying every number." 14 
In my own work with school children, it was already apparent that the "enigmatic highest point at which the rock reversed direction" 15 was certainly not at all enigmatic. Rather, they had to develop the ability to consider this very explicitly in order to point out which consequence can be derived from the fact that the stone always swings in the same plane. Then the school children sat up and took notice: "It intrinsically always stays a little at the peak of its swing." "It has a small point in the air where it stops." "At, at the end. At the endpoint." Furthermore, in the distress to point out exactly where the stone stopped, the children ultimately remained certain: "It [the point where it stops] is always changing," and yet: "Here! At its outermost position." "It has to stop there, but one does not see that."

The certainty that the stone must stop, even if one "does not see it," arises understandably from the bodily experience of the necessity of the point of rest, provided that one moves back again in the same way that one had moved forward. It is an unthematic, guiding horizon of the understanding that found convincing expression in the case of a school girl when, endeavoring to decide whether the rock only turns around or whether it really stops, she said as she moved herself parallel and following the swinging motion of the piece of rock back and forth, back and forth, "It always goes like this!"

In this horizon of experience and understanding, however, there is at the same time the grounding of opposition or resistance to the thought of a "standing-still without duration," or rather to the notion of speed as a series of moments. Either something is in motion, in which case it is not at rest, or if it is at rest, standing still, then it has duration-"for a second," a "tenth," or a "hundredth of a second" or "the bare minimum," but it has duration! Thus the school children persisted still further: "It [the stone] must require time." "It certainly has to have some duration." But a standing-still without duration? "No," said one child abruptly, "I cannot imagine that!"

As a matter of fact, for the students the pendulum was less a theoretical object, or even something of physical interest, but instead the "highest point" of the rock's swing was "mysterious." But what, then, should the students ask about since for them the cause of the pendulum's motion had been known all along? As a first cause, then, if the rock became deflected or turned outward, they were led to themselves or to their teacher. Obviously the rope with the falling rock swings in a definite path. Thus, thought the students, just like a car that "rolls down a mountain," the rock "gets into the swing" that is necessary for the pendulum. It was also obvious to the students that the rock never again swings as high as it did previously, and that it finally comes to rest. With every movement of the pendulum, the stone evidently "lost" something from its swing.

At this point you might want to object that "swing" has been understood as being something like energy, which cannot be lost or de- 
stroyed, and that there was still the friction in the suspension and the resistance of the air, among other things, remaining to be considered. Consequently, the students too had developed a misconception. To argue in this way, however, is to say that the students and their observations were measured against and from within a point of view that they simply did not have: namely, from the point of view of physics, instead of from that of the pre-understanding that, in fact, serves as a basis and guide for their observations. This latter is the point of view from the pre-understanding of the lifeworld. A very elementary, guiding horizon of the understanding is that which is implied by change and the experience of change as becoming and as passing away. This is change to which all appearances and events in nature are ultimately subject and one which is also able to take place slowly. Finally, it is also for this reason that the rock very obviously does not swing as high as previously for "it cannot swing by itself without that which somehow gives it push." As another student said, "It is exactly the same as with a swing set. If one is sitting on the swing now, then it will also always go less and less, if one isn't always ... ah, one also has always to go back and then get the swing."

Please understand the fundamental experience at work here: there is nothing without a cause, in particular there is no movement without a cause, and without a cause it is also the case that a movement cannot sustain itself. Therefore the rock "always requires a starting push if it is to swing further."

If everyday experiences and observations have come to be considered as misconceptions following the measurements of physics, then this too is a conception which is, if you will allow me to play on words, a misconception. Everyday experiences and observations have both a proper false and a proper correct to them that arise from their correspondence to the functioning structures of the lifeworld. One finds that something other than theoretical concepts has come to be subsumed under such colloquial expressions as "speed," "movement," etc. They are "playgrounds of experience!" The colloquial expressions fulfill their task not in opposition to, but rather because of their "inexactness" or "imperfection" to be useful in the different situations of daily life, to gain the required precise sense in the course of these situations, and in so doing to guarantee the ability to get along well in more satisfactory ways. Such a getting-along-well is to be constitutive for our confidence in the reliability of sensuous perception, a confidence that will not as a rule be shaken by deceptions of the senses because such deceptions as a rule become evident through sense perception. Furthermore, objectifying observation itself presupposes the reliability of sense perception.

Cognition or reflection as they occur in physics usually do not lead to a better understanding of the everyday use of something. How 
should reflection about the physics of a plaything, for example, lead to a better playing? Or how should knowledge of the law of levers lead to one's being better able to drive a car? The reflections one entertains in physics, and this is true as a rule for other theoretical reflections, do not have the horizon of the lifeworldly-practicality of the use of something in view, but rather such reflections are concerned with the methodical validity of their cognition.

Physics is neither the setting forth in other means of the activity or business of daily life, nor does it lie on the plane and in the direction of the originary, the projection of our being-toward-the-world as grounded in the lifeworld. Rather, it is the historia naturalis, which Hans Lipps emphasizes and translates as "knowledge of nature" (Naturkunde) that one finds on the plane and in the direction of the originary. Above all, "it was the strange, which was reported as noteworthy, or the unusual, which would be collected."16 This "historia naturalis" was connected with "aesthetic contemplation," and the researcher was the witness to a happening. The ability to witness in this way, however, is no longer something to which the physicist has direct access.

Nonetheless, physics is unable to do without the lifeworld as its own foundation of sense, even if it is a "forgotten foundation of sense" as Husserl said. The principal difference between the lifeworld and the standpoint of physics indicates the problem associated with the learning of physics, namely that there are not two or even three worlds we encounter, but rather there is only one world without which, on the one hand, "all the symbols of science remain, or rather were, insignificant." ${ }^{17}$ On the other hand, it happens that, from the point of physics, a radical, new interpretation takes place to such a degree that what is conceptualized as a concept in physics is never to be found in experience, and further the sense of such a concept always contradicts what the experience of daily life teaches.

The imminent difficulty with the learning of physics comes about to the extent that it takes place not as a continuous "learning that," but rather it takes place essentially as a re-learning.

\section{On the Imminent Difficulty with the Teaching of Physics}

In re-learning, the learner must "break" with the way of his everyday being-toward-the-world. There is no reproach to be found in this and nothing for which one has to make up. The "breaking" marks only the particular difficulty and the particular problem associated with the learning of physics from the beginning. The problem is that the constitution of a first horizon of the understanding, which is fundamental for all further learning of physics and for the sense of events and things in the world as seen by physics, is actually first to be established-and that, as Galileo has said, it goes against the 
"most openly contradictory sense impressions." Under no circumstances does the learning of physics permit itself to be carried out in the manner of a process that would make the experience of sensuous, perceptible events, which until then were ideal-exact Limesgestalten, more precise.

The learning of physics takes place, rather, in terms of the aporia with perceptions of the nonphysical, which are themselves still carried out as living and as from the perspective of the lifeworld; it is an aporia that itself projects a corresponding, unthematic, guiding horizon of the understanding to the learner. If in an aporia-like situation no guiding horizon of the understanding projects itself to the learner in which the Limesgestalten of physics would at least be a foreshadowing, then the learner will understand in the future what he previously, unthematically, had already understood: that there cannot be a movement without a cause and that a "standing-still without duration" is not to be thought. Every experiment, every series of investigations, their results, and their presentation in classes presupposes in advance the guidance of a sufficiently differentiated horizon of the understanding. This is the case regardless of whether a course of instruction is understood as an "order or arrangement" according to curricular principles "planned in advance and thereby also of fixed order," uncomplicated demonstrations."19

Such a horizon, however, is simply not present at hand in a natural manner for the pre-understanding of the lifeworld, nor is it present at hand when the physiognomy of daily routine is subjected to an ever-faster change through the mediating products of the modern natural sciences. The lifeworld will not be made more scientific as physics will not be made more unscientific by a physicist, for example, speaking of an electron "seeing" the lattice structure of a crystal. In daily life the indirect or mediated products of the modern natural sciences refer to physics at best in terms of the unconceptualized, but perhaps also in terms of the unconceptualizable, or even in terms of the threatening ground of its production.

The discontinuity of the learning of physics in re-learning, which is grounded in the principal difference between the lifeworld and the standpoint of physics, also reveals the fundamental problem of teaching of physics. This is the problem of the suggesting, or rather of the initiating, of a qualitative "leap" in which the constitution of a horizon of the understanding as found in physics shows itself. This "leap" occurs in a way that is similar to the "springing forth" of a sought-after figure in a picture puzzle. The re-learning can come to be suggested, or rather initiated, by the understanding of examples. This understanding of example can be made possible through the confrontation with the unthematic, guiding horizon of the under- 
standing, and the projection of a first, unthematic, guiding horizon of the understanding of the sort associated with physics. In this regard, then, the understanding, which is actually first, would become an understanding of what the given example was an example of.

I cannot thematize the understanding of examples any further here because to do so would require a separate paper. ${ }^{20}$ There exist as yet unclarified, but nonetheless essential questions concerning the learning and teaching of physics. For example, the question can be posed concerning those idealizations of the lifeworld-which are still not the Limesgestalten of physics - which, however, could refer to an understanding of examples to the direction of the constitution of a horizon of the understanding of physics.

Similarly, the question can be posed concerning the learning and teaching after the constitution of a first horizon of the understanding pertaining to physics. The anticipation of the new horizon cannot at first have the same quality as the horizons of the lifeworld, which then in turn no longer have their previous validity. And then there is the question as to whether the new understanding of physics could ever come to achieve the quality of the old one, or whether it does not express itself in the often-deplored relapse of school children into everyday theories, thus illustrating even more distinctly what Merleau-Ponty had said regarding science in general: "Science will never have the same 'sense of being' as the world of experience for the simple reason that as such it is determination or explanation."21

\section{On the Psychology of Learning}

You might ask at this point, however, as to whether other disciplines, and in particular research into the psychology of learning, have not already answered all of the questions pertaining to the learning of physics. I am convinced that the criticism by McLeod, to the effect that we know almost all there is to know about the training of rats and pigeons and that we have very beautiful mathematical models of learning--but that we just do not know what goes on in the heads of children, is not yet out of date for empiricist research into learning even today. ${ }^{22}$ Furthermore, every position that reduces learning to an intellectual or cognitive process misses the learning itself since in so doing it does not have in view the decisive dimension of learning, namely the pre-reflective, unthematic, guiding pre-understanding, particularly with respect to re-learning.

But the learning of physics does not just mean re-learning with respect to the constitution of the originary, first horizon of the understanding that is fundamental for any further learning of physics. It also means that the instances of "having simultaneously known," which are only indistinct and vague within this horizon, must come 
to be brought to sufficiently clear knowledge by means of re-learning, by means of the verification of and disappointment about what has been anticipated from within the horizon.

Piaget concerns himself in his own research with drawing out his notion of "sensory-motor intelligence" starting with the development of thinking from the pre-reflexive up to its perfect outward form. However, he presupposes thinking to be a process of development that finds its fulfillment in the grouping of formal-mathematical thought and which, with the first schema of the pre-reflexive, was already on the way toward sensory-motor intelligence development and which, at about 11 or 12 years of age, will finally have come to be worked out. ${ }^{23}$ According to Piaget, the pre-reflexive, the phenomenologically-seen, lasting, and "permanent ground of all cognitive performance" ${ }^{24}$ only serves to disappear in the rationality of formal thinking; and this formal thinking should be the thought that serves as the basis for the sciences.

In this way, the question concerning the learning of physics is restricted to a corresponding supplement to the development of a natural thinking. I am unable to see how theories, which actually agree neither with the peculiarity of human being-toward-the-world, nor with the peculiarity of the objects of learning, can contribute to a correct understanding of the learning of physics.

Piaget also scarcely concerns himself with the peculiarity of concepts from physics, even in the cases where he investigates the development of such concepts. ${ }^{25}$ Thus, with the representation of the invariance of a weight, he sees that the concept of weight as understood in physics was also given. The only problem here is that, when seen from the standpoint of physics, the weight of a body is not invariant, but rather changes according to its place on and its distance from the surface of the earth.

From the phenomenological perspective, the basic problem for the teaching and learning of physics is found in the notion of the learning of physics as re-learning. It is true that there are opposing interpretations of the learning of physics. The question, however, is which of these interpretations of the learning of physics also corresponds to its essence- - which will not allow itself to be decided as we "nevertheless continue to want to construct the form of this world, life, perception, and spirit, instead of recognizing in the experience we have of all of them the nearest source and the ultimate standard of all knowledge." ${ }^{26}$

\section{Notes}

1. This article is based on a more detailed presentation at a conference on Physics Education, August 20-25, 1984, Utrecht, Holland. I thank Dr. R. Taft (Loyola University) for his assistance with the translation of the first draft. 
2. See A. Koyre, Newtonian Studies, (London: Chapmann u. Hall, 1965), p. 269, in comparison with Neue Hefte für Philosophie, 2/3, 125 (1972) See also G. Freudenthal, Atom und Individuum im Zeitalter Newtons, (Frankfurt: Suhrkamp Verlag, 1982), p. 21.

3. R. Carnap, Physikalische Begriffsbildung, (Darmstadt: Wissenschaftliche Buchgesellschaft, 1966), p. 5.

4. C. F. von. Weizsäcker, Die Tragweite der Wissenschaft, (Stuttgart: Hirzel Verlag, 1971), p. 107.

5. C. F. von. Weizsäcker, (1971), p. 107.

6. G. Galilei, Sidereus Nuncius Nachricht von neuen Sternen, (Frankfurt am Main: Suhrkamp taschenbuch wissenschaft 337, 1980), p. 210.

7. G. Galilei, Unterredungen und mathematische Demonstration über zwei neue Wissenszweige, die Mechanik und die Fallgesetze betreffend, edit. A. v. Oettingen (Darmstadt: Wissenschaftliche Buchgesellschaft, 1973), p. 162 .

8. G. Galilei, (1973), p. 162.

9. G. Galilei, (1973), p. 163.

10. G. Galilei, (1973), p. 65.

11. M. Merleau-Ponty, Phänomenologie der Wahrnehmung, (Berlin: Walter de Gruyter, 1966), p. 313.

12. M. Merleau-Ponty, (1966), p. 423.

13. M. Merleau-Ponty, (1966), p. 5.

14. M. Wagenschein, Naturphänomene sehen und verstehen, (Stuttgart: Klett-Verlag, 1980), p. 102.

15. See H. Freudenthal, Raumtheorie, (Darmstadt:Wissenschaftliche Buchgesellschaft, 1978), p. 399.

16. H. Lipps, Die Wirklichkeit des Menschen, (Frankfurt am Main: Vittorio Klostermann, 1954), p. 12.

17. M. Merleau-Ponty, (1966), p. 4.

18. K. H. Schwager, Wesen und Formen des Lehrgangs im Schulunterricht, (Weinheim: Beltz Verlag), p. 112.

19. M. Wagenschein, (1980), p. 102.

20. See: B. Redeker, Zur Sache des Lernens-am Beispiel des Physiklernens, (Braunschweig: Westermann-Verlag, 1982, above all chapter II 5.3; IV 2.4.2, 3; V 1,2,3). K. Meyer-Drawe, Lernen als Umlernen, in: W. Lippitz/K. Meyer-Drawe, Lernen und seine Horizonte, (Königstein i. Taunus: Scriptor-Verlag, 1984, 2. Auflage). K. Meyer-Drawe, Vierteljahresschrift für wissenschaftliche Pädagogik, 4, p. 515, (1982). G. Buck, Lernen und Erfahrung, (Stuttgart: Kohlhammer Verlag, 1969, 2. Auflage).

21. M. Merleau-Ponty, (1966), pp. 4-5.

22. R. B. McLeod, American Psychologist, 20, (1965), p. 347, in comparison with H. Skowronek, Lernen und Lernfähigkeit, (München: Juventa Verlag, 1974, 5. Auflage), pp. 69-70.

23. J. Piaget, Psychologie der Intelligenz, (Freiburg im Breisgau: Walter Verlag, 1972, 5. Auflage), p. 140.

24. K. Meyer-Drawe, (1984), p. 515.

25. J. Piaget, Die Entwicklung der physikalischen Mengenbegriffe beim Kinde, (Stuttgart: Klett Verlag, 1969)

26. M. Merleau-Ponty, (1966), p. 43. 